Esta revista forma parte del acervo de la Biblioteca Jurídica Virtual del Instituto de Investigaciones Jurídicas de la UNAM

\title{
LA FISCALÍA GENERAL DE LA REPÚBLICA EN LA CONSTRUCCIÓN DEL ESTADO DE DERECHO
}

\author{
Jorge MADRAZO
}

\begin{abstract}
SUMARIO: I. La Fiscalía General y el Estado de derecho; una tarea medular. II. La autonomía del fiscal general y de los fiscales especializados.
\end{abstract}

\section{LA Fiscalía General y EL EStAdo DE DERECHO; UNA TAREA MEDULAR}

México como nación independiente no ha vivido sino eventualmente bajo el Estado de derecho en su significación de imperio de la ley, es decir, bajo el principio de que la autoridad sólo puede hacer lo que la ley le autoriza y los particulares pueden hacer todo excepto lo que la ley les prohíbe. Después se pueden agregar muchos predicados al enunciado, pero sin éste no son un Estado de derecho.

Los posibles orígenes históricos de este "problema madre" ciertamente son remotos y vienen, por lo menos, desde el Virreinato, pero han impedido que los sistemas y las instituciones funcionen adecuadamente, lo que genera la impunidad, apuntala la corrupción, autoriza vivir en la mentira y en la simulación, no combate la pobreza y provoca la desigualdad y la inequidad.

Este problema no sólo incumbe al gobierno sino también a toda la sociedad, en tanto que supone una forma de pensar, unos principios, un conjunto de creencias, unas actitudes y unas conductas que muchos comparten y que se concretan no sólo en el no cumplimiento voluntario de la ley, sino francamente por el desprecio a los mandatos obligatorios, se sea gobernante o gobernado. Al paso de los años y de la acumulación de tales tendencias de muchos mexicanos, realizadas muchas ve-

\footnotetext{
* Universidad Nacional Autónoma de México, Seattle.
} 
Esta revista forma parte del acervo de la Biblioteca Jurídica Virtual del Instituto de Investigaciones Jurídicas de la UNAM

ces, tal parece que el subconsciente colectivo del país automáticamente responde rechazando la ley, la ley no sólo como norma legislada, sino también como mandatos de otras autoridades.

La acumulación de episodios cotidianos de incumplimiento de la ley o de simulación, hacen que hoy, ante la crisis de las crisis, México no tenga otra alternativa que reconocer la existencia del problema que como he dicho no es partidista, no es ideológico, ni es político, sino es esencialmente cultural.

Su esencia cultural no le resta importancia como algunos han creído, sino por el contrario, hace que se comprenda su envergadura y la dificultad en su solución.

Para este problema no hay soluciones ni fórmulas fáciles, rápidas y baratas.

Pensemos cuál sería la alternativa a esta opción. ¿Acaso el Estado de excepción y el régimen de suspensión de garantías para combatir a las organizaciones criminales y restablecer la paz pública? ¿Tener de facto un régimen así, aunque no se sigan los procedimientos de la suspensión?

En mi concepto sólo con un cambio en la forma de pensar de muchos mexicanos, es decir, de un verdadero cambio de la cultura, es como México tiene futuro y entonces sí, los nuevos sistemas, leyes y reformas constitucionales podrán tener la posibilidad real de funcionar como se diseñaron, se podrá abatir la criminalidad galopante y se volverá a una real seguridad pública con pleno disfrute de los derechos humanos.

No es un cambio rápido, pero es el más seguro, el más humano y el único sustentable.

Este cambio debe ser impuesto al gobierno por la sociedad organizada, pero es el propio gobierno el que debe modelar el cambio para que éste sea creíble y sea seguido por la mayoría de los mexicanos.

Debe quedar claro que ningún sistema de enjuiciamiento criminal se diseña para ser ejecutado sobre la mayoría de la población, sino por el contrario, puede operar respecto de una minoría significativa. Es decir, la ejecución coactiva de la ley a los remisos en su cumplimiento debe darse respecto de unos pocos, dado que unos muchos aceptan y cumplen voluntariamente la ley.

Las reformas constitucionales y legales de 2008, 2011 y 2014, cargadas de buenas intenciones y la mayoría de ellas técnicamente bien elaboradas, carecen de los cimientos para sostenerse, como ha pasado, con diferente intensidad, en nuestra historia de nación dependiente e independiente.

Si fuésemos capaces de aceptar el desafío y ser valientes como para reconocer el problema arriba descrito, cuya solución arranca en los 
Esta revista forma parte del acervo de la Biblioteca Jurídica Virtual del Instituto de Investigaciones Jurídicas de la UNAM

hogares, en la sobremesa, en la conversación de padres e hijos, en el seno de las tradiciones de las familias mexicanas; en la medida que podamos verdaderamente educar a los hijos en valores, comunicar principios, dar ejemplo, corregir desvíos, entonces debiéramos trazar una estrategia con acciones de largo plazo que empiecen a trabajar sobre los cimientos de las leyes y las instituciones, acompasarlas con soluciones de más corto plazo para que estas últimas, de manera excelente, realicen los fines para las que fueron creadas

La rebeldía social ante la ley puede explicar el pasado, pero es la garantía del fracaso mirando hacia el futuro.

Me ilusiono al pensar que la nueva Fiscalía General de la República pueda cumplir esta misión de modelar el cambio, es decir, el cambio en el modo de pensar de sus integrantes, al tiempo de cumplir cabalmente con las responsabilidades que las reformas constitucionales le han asignado. Sólo así tiene futuro y tienen sentido las decisiones fundamentales sobre los sistemas acusatorio y adversarial, los juicios orales, los procedimientos abreviados, las fórmulas alternativas, los jueces de control, las garantías de transparencia, el principio pro-persona, etcétera.

La única manera en que la Fiscalía pueda cumplir esta doble función, como modelo del cambio eficiente y humanista, por una parte, y órgano de acusación en el sistema de enjuiciamiento, por la otra, es mediante el ejercicio de una autonomía plena.

\section{LA AUTONOMÍA DEL FISCAL GENERAL Y DE LOS FISCALES ESPECIALIZADOS}

Sólo siendo plenamente autónoma, la nueva Fiscalía puede salir airosa de un desafío de tal trascendencia. Ahora por razones coyunturales está dado el momento para producir este cambio tan anhelado, bajo condiciones que muy seguramente no se volverán a repetir, es decir, empezar de cero, me parece. En todo caso, la autonomía debe suponer ausencia total de sometimiento, de negociaciones y de complacencias.

Si la nueva Fiscalía en la persecución de los delitos federales y las graves violaciones a los derechos humanos da resultados de legalidad, imparcialidad, celeridad, eficacia honradez y justicia, trabajando con una actitud humanista que privilegia los derechos de la persona, estará precisamente modelando el cambio que México necesita en muchas áreas de la vida colectiva.

Ahora se trata de un nuevo comienzo, y por eso hay que ser profundamente innovador y audaz en la percepción del futuro con una total 
claridad de las metas que se desean alcanzar. Desde luego el cambio no puede ser solo de membrete, o como a muchos mexicanos les gusta: Cambiar para seguir siendo lo mismo. Reformar la Constitución y las leyes para preservar el statu-quo. Como dice aquella frase tristemente célebre: "En México hagas lo que hagas, no pasa nada".

La autonomía del fiscal, que debe permear a toda la institución, tiene diversas expresiones. La autonomía técnica, que implica que el fiscal resuelva todo asunto, todo el tiempo, de acuerdo con lo que marcan las normas y los principios que las inspiran, y nada más. A partir de la reforma de 2011 el Ministerio Público habrá de pensar humanísticamente, es decir, deberá interpretar las normas por aplicar tomando en cuenta los derechos humanos reconocidos en la Constitución y en los tratados internacionales.

Ha de ser independiente de los tres poderes, de los órganos de la sociedad y desde luego de los poderes informales. No se trata de autonomizarse del ejecutivo para pasar a depender del Senado, de las ONG's, o de otros organismos sociales.

Como un órgano constitucional que no está inscrito en ninguno de los poderes constituidos, la Fiscalía ha de tener autonomía financiera, para poder contar con un presupuesto digno que le permita realizar todas sus funciones. La autonomía financiera no es barata.

El fiscal general, los fiscales especiales y el resto de los integrantes del Ministerio Público Federal deberán contar con las garantías para el ejercicio de su autonomía de manera similar a las garantías jurisdiccionales de las que gozan los jueces federales en materia de: nombramiento, remoción, permanencia, ingresos, promociones y rendición de cuentas. Para empezar, el fiscal general ha de tener el mismo sueldo y prestaciones, incluido el retiro, que un ministro de la Suprema Corte.

Debe quedar claro que los cargos de fiscal general de la República y de los fiscales especializados no son cargos políticos, sino técnicojurídicos de la mayor jerarquía.

La tarea de asegurar estas garantías para el Ministerio Público Federal puede lograrse mediante la integración de un órgano que sea reflejo del Consejo de la Judicatura Federal, formado por personas nombradas por el Ejecutivo, el Legislativo, la academia, las ONG's de derechos humanos y las asociaciones de abogados.

Bajo el principio de la corresponsabilidad de los poderes públicos y de la sociedad organizada y participativa, cada una de las entidades citadas arriba nombrará a un solo representante, hasta tener cinco, órgano que por mayoría de votos decidirá sobre el ingreso, promoción y per- 
LA FISCALÍA GENERAL DE LA REPÚBLICA...

manecía de los fiscales y de toda la estructura del Ministerio Público. El dicho Consejo contará con el personal de apoyo que resulte necesario.

Como quiera, el Senado declarará cuando se hayan dado las condiciones para asegurar que el colectivo de abogados y de ONG's-academia se han constituido. Mientras esto suceda el propio Senado de manera alternativa decidirá a qué organización corresponderá hacer el nombramiento de representante ante el Consejo del Ministerio Público Federal, circunstancia que no podrá prorrogarse por más de dos procesos de nombramiento.

Cada uno de tales colectivos, de acuerdo con sus propias reglas, procesará el nombramiento de su representante.

Las decisiones del Consejo del Ministerio Público se tomarán por mayoría de los presentes, y no serán recurribles.

En cuanto a nosotros, los abogados que somos los actores principales en esta obra, válidamente debemos preguntar dónde quedó nuestra reforma. Me refiero a la proliferación de las universidades "patito" que otorgan títulos que denigran nuestra profesión. ¿En dónde está la barra nacional y la colegiación obligatoria? ¿En dónde está el trabajo por los justiciables pobres?

El fiscal general será nombrado por el Consejo del Ministerio Público Federal de la propuestas que envíe el presidente de la República, la Cámara de Senadores, el colectivo de las ONG's y la academia, y, finalmente, el colectivo de las asociaciones de abogados de alcance federal.

El Instituto Nacional de Ciencias Penales (Inacipe), dependiente del Sistema Nacional de Seguridad Pública, realizará un examen de conocimientos, previa convocatoria pública, a fin de que todos aquellos que aspiren a ser fiscal general, fiscales especiales o agentes del Ministerio Público, realicen y aprueben satisfactoriamente dicho examen, que abarcará las áreas de conocimiento relacionados con la posición a la que se aspira.

El Inacipe también realizará los exámenes de control de confianza que correspondan y que abarcarán el polígrafo, la prueba toxicológica, la psicológica y la de situación patrimonial.

Sólo aquellos candidatos que aprueben satisfactoriamente dichos exámenes y cuenten con el certificado correspondiente podrán ser nominados ante el Consejo del Ministerio Público Federal. Esto es aplicable desde luego para el fiscal general y los especializados, y toda la planta del Ministerio Público.

En la realización de estas tareas, el Inacipe será supervisado por el Consejo del Ministerio Público. Los exámenes se realizarán por lo menos una vez al año. 
Esta revista forma parte del acervo de la Biblioteca Jurídica Virtual del Instituto de Investigaciones Jurídicas de la UNAM

En cuanto a la remoción del fiscal general y de los especializados, sólo procederán por causa grave a juicio del Consejo del Ministerio Público Federal, y el voto de las dos terceras partes de los presentes en el Senado de la República. Los organismos de la sociedad podrán hacer llegar sus opiniones al Senado antes de que éste decida sobre la remoción o permanencia del correspondiente fiscal.

Los servicios periciales también debieran depender de una instancia ajena a la Fiscalía General, para así ofrecer más seguridades sobre la imparcialidad de los dictámenes y las decisiones ministeriales. Creo que la creación de un Centro Nacional de Servicios Periciales, bajo la supervisión del Consejo del Ministerio Público Federal y que pueda servir a varias instituciones, pero que sepa responder con celeridad y eficacia a las necesidades de los fiscales es muy recomendable.

Me parece que en la Procuraduría General de la República trabajan muchos servidores públicos honrados y eficientes que deben tener la oportunidad de continuar colaborando en la nueva institución. Para que ello suceda, deberán tener el primer turno para presentar en el INACIPE las pruebas de conocimientos y de control de confianza. Aquellos que fuesen certificados formarían parte de la nueva Fiscalía.

Finalmente en cuanto a las policías, sólo espero fervientemente que en estos años de vacatio legis se hayan formado los ministerios públicos como los auténticos líderes de la investigación criminal y que los agentes de policía reconozcan tal liderazgo en la investigación de todos los delitos, siempre.

Si efectivamente esto se dio, elemento que francamente desconoz$\mathrm{co}$, creo que los policías podrían permanecer en sus corporaciones si se someten al mismo procedimiento de acreditación que los responsables del Ministerio Público. Tienen derecho a ello y si son certificados deben ser retenidos en sus puestos. De esta manera yo estaría muy tranquilo con respecto a la reforma al 123 sobre la no procedencia de la reinstalación cuando mediara una resolución de despido injustificado. También con respecto de las policías, este proceso implica un nuevo inicio.

Con razón se podría afirmar que las modificaciones que propongo tomarán plazos largos y costosos, y la respuesta sería afirmativa. Pero si esto puede ser el inicio de una transformación del país, creo que vale la pena invertir en lo que más importa, que es asegurar un mejor México para los mexicanos que vienen. 